\title{
MRI for Assessment of Anal Fistula
}

\author{
Saeed Naghibi ${ }^{1, *}$ \\ ${ }^{1}$ Islamic Azad University \\ "Corresponding author: Saeed Naghibi, Islamic Azad University. E-mail: naghibisaeed42@gmail.com
}

Received 2016 December 21; Accepted 2017 February 08.

\begin{abstract}
Abstract: A fistula-in-ano is the passage between the skin around the anus and anal canal that usually caused by a previous anorectal abscess and an obvious sign of that is continuous discharge. Although it's not the common disease in GI tract but it has caused considerable morbidity. The outbreaks have almost 11 per 111, 111, and 2 - 4 times more frequent in men and if it's not diagnosed and treated on time, it can be a high risk of recurrence and fecal incontinence and associated risk of sepsis and abscesses.

Objectives: The purpose of the study was to evaluate the role of Magnetic Resonance Imaging in detection and characterization of perianal fistulae and correlating it with surgical findings.

Methods: In this study, 14 patients with clinical and physical examination of perianal fistulas were prospectively selected for MRI evaluation, with specific MRI sequence T1W, T2W, T1 Fat Sat or T2 Fat Sat, T1 + contrast, etc,and with special coils plans axial, coronal, sagittal. MRI findings were recorded. The surgery was performed and the results were also recorded and eventually the consistency and effectiveness of MRI were compared with the results after surgery.

Results: Amongst the total of 14 patients,in 1 patient (7117) Transsphincteric fistula, 11 patients (78167) Intersphincteric fistula and 2 patients (14137) Suprasphincteric fistula were diagnosed and in surgery findings, 1 (7117) Transsphincteric fistula, 11 (71147) Intersphincteric fistula and 2 (14137) Suprasphincteric fistulas were detected and in one case no fistula was observed. An agreement between two detection methods was 82177 and sensitivity of MRI in the diagnosis of intersphincteric, transsphincteric and suprasphincteric fistulas were 1117 and the specificity was 757 in the detection and diagnosis of intersphincteric fistulas and 1117 for transsphincteric and suprasphincteric fistulas1

Conclusions: Based on the results of this study and according to the 1117 sensitivity of MRI, it's useful to locate the perianal fistulas, reduce the chance of recurrence and postoperative complications and can contribute the healing process better than other diagnostic methods.
\end{abstract}

This is an abstract presented in the 33rd Iranian congress of radiology (ICR) and the 15th congress of Iranian radiographic science association (IRSA) 